\title{
Methylation of the DLEC1 gene correlates with poor prognosis in Japanese lung cancer patients
}

\author{
HIDEFUMI SASAKI, YU HIKOSAKA, OSAMU KAWANO, \\ SATORU MORIYAMA, MOTOKI YANO and YOSHITAKA FUJII \\ Department of Oncology, Immunology and Surgery, Nagoya City University \\ Graduate School of Medical Sciences, Nagoya 467-8601, Japan
}

Received September 7, 2009; Accepted December 2, 2009

DOI: 10.3892/ol_00000050

\begin{abstract}
The incidence of chromosome $3 p$ gene alterations is one of the most frequent and earliest documented events in lung cancer. This study aimed to investigate promoter methylation in the deleted in lung and esophageal cancer 1 (DLEC1) gene, as well as the pl6 and CDH1 genes in Japanese lung cancer cases. The methylation status of the promoter regions of $D L E C 1, p 16$ and $C D H 1$ was investigated using methylation-specific PCR. The findings were compared to the clinicopathological features of lung cancer. Methylation-specific PCR showed that the DLEC1 promoter region was methylated in 65 out of $116(56 \%)$ lung cancers. Patients with DLECl-methylated cancer were associated with a significantly worse prognosis than those with unmethylated cancer $(\mathrm{p}=0.0368$; hazard ratio $=1.83$ ). The p16 methylation status correlated with squamous histology ( $\mathrm{p}=0.03$ ) and smoking status (never smoker vs. smoker; $\mathrm{p}=0.0122$ ). Patients with pl6 ummethylated cancer harbored more EGFR mutations ( $\mathrm{p}=0.0071)$. The $C D H 1$ promoter region was hypermethylated in 65 out of 118 (55.1\%) lung cancer cases. However, the $\mathrm{CDH} 1$ methylation status was not associated with the clinicopathological characteristics of the lung cancer types. pl6 and $\mathrm{CDH} 1$ methylation status did not correlate with survival in the lung cancer patients. Thus, in our Japanese cohort, the methylation status of the DLEC1 gene was a marker of poor prognosis independent of stage.
\end{abstract}

\section{Introduction}

Alleic loss of chromosome $3 p$ is one of the most frequent and earliest documented events in lung cancer with a wide range of $3 p$ mutations (12-26), suggesting the presence of multiple

Correspondence to: Dr Hidefumi Sasaki, Department of Oncology, Immunology and Surgery, Nagoya City University Graduate School of Medical Sciences, 1 Kawasumi, Mizuho-cho, Mizuho-ku, Nagoya 467-8601, Japan

E-mail: hisasaki@med.nagoya-cu.ac.jp

Key words: methylation, DLEC1 gene, lung cancer tumor-suppressor genes on $3 p$ (1-3). The chromosome locus 3 p22.3 is a 'hot spot' for chromosomal aberrations and loss of heterozygosity in cancers, including lung cancer $(4,5)$. Further analysis led to the identification of the $D L C l$ gene (6), which was later renamed deleted in lung and esophageal cancer 1 (DLEC1) on 3p22.3. Loss of DLEC1 expression has been observed in lung, esophageal, renal, ovarian and nasopharyngeal carcinoma cell lines and primary tumors. Moreover, functional analyses strongly suggest that DLEC1 is a tumor-suppressor gene (6-8). Promoter hypermethylation has been shown to be responsible for the silencing of DLEC1 in ovarian cancer and nasopharyngeal carcinoma $(7,8)$. Furthermore, there have been methylation analyses reported for hepatocellular carcinoma (4), gastric (9) and lung cancers (5).

This study investigated whether the promoter hypermethylation of DLEC1 plays a role in lung cancer in Japanese patients, and whether it has any prognostic significance. The methylation status of the promoter regions of DLEC1 was investigated using methylation-specific PCR. The findings were compared to the clinicopathological features of lung cancer.

\section{Patients and methods}

Patients. The study group included lung cancer patients who had undergone surgery at the Nagoya City University Hospital. Written informed consent was obtained. Approval was granted by the Institutional Ethics Committee of the Nagoya City University Graduate School of Medical Sciences. The lung tumors were classified according to the general criteria for the clinical and pathological record of lung cancer in Japan (10). Tumor samples were immediately frozen and stored at $-80^{\circ} \mathrm{C}$ until assayed. The clinical and pathological characteristics of the 116 lung cancer patients for DLEC1 sequencing analysis follow. Eighty-nine patients $(76.7 \%)$ were male, 27 were female. Thirty-eight patients $(32.8 \%)$ had squamous cell carcinomas; 65, adenocarcinomas and 10 had adenosquamous cell carcinomas. Eighty-five (73.8\%) were smokers and 31 were non-smokers. The clinical and pathological characteristics of the lung cancer patients for the methylation analyses are documented in Tables I, II and III, respectively. The samples from these patients were previously sequenced for EGFR (11-14). 
Table I. Clinicopathological data of 116 lung cancer patients.

\begin{tabular}{|c|c|c|c|}
\hline \multirow[b]{2}{*}{ Factors } & \multicolumn{3}{|c|}{$D L E C 1$ gene status } \\
\hline & Methylated cases & Unmethylated cases & $\mathrm{p}$-value \\
\hline Mean age (years) & $64.5 \pm 8.9$ & $66.3 \pm 13.3$ & 0.2211 \\
\hline Stage & & & 0.7028 \\
\hline I & $24(36.9 \%)$ & $21(41.2 \%)$ & \\
\hline II-IV & $41(63.1 \%)$ & $30(58.8 \%)$ & \\
\hline Lymph node metastasis & & & 0.5734 \\
\hline No & $34(52.3 \%)$ & $30(58.8 \%)$ & \\
\hline $\mathrm{N}^{+}$ & $31(47.7 \%)$ & $21(41.2 \%)$ & \\
\hline Smoking & & & 0.2910 \\
\hline Never smoker & $20(30.8 \%)$ & $11(21.6 \%)$ & \\
\hline Smoker & $45(69.2 \%)$ & $40(79.4 \%)$ & \\
\hline EGFR status & & & 0.1657 \\
\hline Wild-type & $49(75.4 \%)$ & $44(86.3 \%)$ & \\
\hline Mutation & $16(24.6 \%)$ & $7(13.7 \%)$ & \\
\hline Pathological subtypes & & & 0.4269 \\
\hline $\mathrm{SCC}$ & $19(29.2 \%)$ & $19(37.3 \%)$ & \\
\hline Non-SCC & $46(70.8 \%)$ & $32(62.7 \%)$ & \\
\hline Age & & & 0.3478 \\
\hline$\leq 65$ & $32(49.2 \%)$ & $20(39.2 \%)$ & \\
\hline$>65$ & $33(50.8 \%)$ & $31(60.8 \%)$ & \\
\hline Gender & & & 0.9999 \\
\hline Male & $50(76.9 \%)$ & $39(76.5 \%)$ & \\
\hline Female & $15(23.1 \%)$ & $12(23.5 \%)$ & \\
\hline
\end{tabular}

$\mathrm{N}^{+}$, lymph node metastasis-positive; SCC, squamous cell carcinoma.

Methylation-specific polymerase chain reaction analysis. DNA was prepared from tissue samples using standard methods. Bisulfite modification of genomic DNA was performed using the MethylCode Bisulfite Conversion Kit (Invitrogen, CA, USA). Briefly, $500 \mathrm{ng}$ of genomic DNA was denatured by incubation with CT Conversion Reagent at $98^{\circ} \mathrm{C}$ for $10 \mathrm{~min}$ and $68^{\circ} \mathrm{C}$ for $2.5 \mathrm{~h}$ and at $4^{\circ} \mathrm{C}$ for several min. Modified DNA was purified by the Spin Column and then eluted with Elution Buffer.

The primer sequences for the DLEC1 gene for methylated (M) sequences were: forward, 5-GTTTCGTAGTTCGGTT TCGT C-3 and reverse, 5-CGAAATATCTTAAATACGCA ACG-3 (107 bp). The primer sequences for the DLEC1 gene for unmethylated (U) sequences were: forward, 5-TAGTTTT GTAGTTTGGTTTTGTT-3 and reverse, 5-ACAAAATATCT TAAATACACACAACA-3. The primer sequences for the $C D H 1$ gene for methylated (M) sequences were: forward, 5-GGTGAATTTTTAGTTAATTAGCGGTAC-3 and reverse, 5-CATAACTAACCGAAAACGCCG-3. The primer sequences for the $C D H 1$ gene for unmethylated (U) sequences were: forward,5-GGTAGGTGAATTTTTAGTTAATTAGTGGTA-3 and reverse, 5-ACCCATAACTAACCAAAAACACCA-3. The primer sequences for the pl6 gene for methylated (M) sequences were: forward, 5-TTATTAGAGGGTGGGGTG GATTGT-3 and reverse, 5-G ACCCCGAACCGCGACCG
TAA-3. The primer sequences for the $p 16$ gene for unmethylated $(\mathrm{U})$ sequences were: forward, 5-TTATTAGAGGGT GGGGTGGATTGT-3 and reverse, 5-CAACCCCAAACC ACAACCATA-3. The cycling conditions were: initial denaturation at $94^{\circ} \mathrm{C}$ for $5 \mathrm{~min}$, followed by 40 cycles at $94^{\circ} \mathrm{C}$ for 45 sec, $65^{\circ} \mathrm{C}(p 16, \mathrm{M}), 60^{\circ} \mathrm{C}(p 16, \mathrm{U}), 58^{\circ} \mathrm{C}($ DLECl, M $), 57^{\circ} \mathrm{C}$ $(C D H 1)$ or $55^{\circ} \mathrm{C}(D L E C l, \mathrm{U})$ for $45 \mathrm{sec}$, and $72^{\circ} \mathrm{C}$ for $45 \mathrm{sec}$.

Statistical analysis. Statistical analyses were carried out using the Mann-Whitney U test for unpaired samples and the Wilcoxon signed-rank test for paired samples. Linear relationships between variables were determined by means of simple linear regression. Correlation coefficients were determined by rank correlation using Spearman's and the $\chi^{2}$-test. Survival of the lung cancer patients was examined by the Kaplan-Meier method, and differences were examined by the log-rank test. Analyses were carried out using the Stat-View software package (Abacus Concepts Inc., Berkeley, CA, USA), and differences were considered significant at $\mathrm{p}<0.05$.

\section{Results}

DLEC1 gene methylation status in Japanese lung cancer patients. Methylation-specific PCR showed that the DLEC1 promoter region was methylated in 65 out of $116(79.8 \%)$ lung 
Table II. Clinicopathological data of 221 lung cancer patients.

\begin{tabular}{|c|c|c|c|}
\hline \multirow[b]{2}{*}{ Factors } & \multicolumn{3}{|c|}{ p16 gene status } \\
\hline & Methylated cases & Unmethylated cases & p-value \\
\hline Mean age (years) & $66.1 \pm 8.9$ & $64.3 \pm 10.9$ & 0.4076 \\
\hline Stage & & & 0.2726 \\
\hline I & $39(43.3 \%)$ & $67(51.5 \%)$ & \\
\hline II-IV & $51(56.7 \%)$ & $63(48.5 \%)$ & \\
\hline Lymph node metastasis & & & 0.1207 \\
\hline No & $51(56.0 \%)$ & $87(66.9 \%)$ & \\
\hline $\mathrm{N}^{+}$ & $40(44.0 \%)$ & $43(33.1 \%)$ & \\
\hline Smoking & & & 0.0122 \\
\hline Never smoker & $15(16.5 \%)$ & $41(31.5 \%)$ & \\
\hline Smoker & $76(83.5 \%)$ & $89(68.5 \%)$ & \\
\hline EGFR status & & & 0.0071 \\
\hline Wild-type & $80(87.9 \%)$ & $94(72.3 \%)$ & \\
\hline Mutation & $11(12.1 \%)$ & $36(27.7 \%)$ & \\
\hline Pathological subtype & & & 0.030 \\
\hline SCC & $49(53.8 \%)$ & $54(38.6 \%)$ & \\
\hline Non-SCC & $42(46.2 \%)$ & $86(61.4 \%)$ & \\
\hline Age & & & 0.2198 \\
\hline$\leq 65$ & $37(40.7 \%)$ & $64(49.2 \%)$ & \\
\hline$>65$ & $54(59.3 \%)$ & $66(50.8 \%)$ & \\
\hline Gender & & & 0.6141 \\
\hline Male & $74(81.3 \%)$ & $101(77.7 \%)$ & \\
\hline Female & $17(18.7 \%)$ & $29(22.3 \%)$ & \\
\hline
\end{tabular}

$\mathrm{N}^{+}$, lymph node metastasis positive; SCC, squamous cell carcinoma.

cancer types. The methylation status of DLECl was not associated with squamous histology (squamous cell carcinoma $29.2 \%$ vs. non-squamous cell carcinoma $37.3 \%$; $\mathrm{p}=0.4269$ ) and smoking status (never smoker $30.8 \%$ vs. smoker $21.6 \%$; $\mathrm{p}=0.291)$. In addition, the DLECI methylation status did not correlate with gender $(\mathrm{p}=0.9999)$, age $(\mathrm{p}=0.3478)$, lymph node metastasis $(\mathrm{p}=0.5734)$ and pathological stages (I vs. II-IV; $\mathrm{p}=0.7028)$. DLEC1 methylation independently existed with EGFR mutations $(\mathrm{p}=0.1657)$.

The pl6 promoter region was methylated in 91 out of 221 (78.8\%) lung cancer types (Table II). The methylation status was correlated with squamous histology $(\mathrm{p}=0.03)$, smoking status (never smoker vs. smoker; $\mathrm{p}=0.0122$ ) and $E G F R$ wildtype $(\mathrm{p}=0.0071)$. However, the pl6 methylation status did not correlate with survival $(\mathrm{p}=0.6215)$.

The $\mathrm{CDH}$ promoter region was methylated in 65 out of 118 (78.8\%) lung cancer types (Table III). A higher frequency of methylation cases of the $\mathrm{CDH} 1$ promoter region was associated with younger patients $(\mathrm{p}=0.0491)$. However, the methylation status did not correlate with survival $(\mathrm{p}=0.8011)$.

DLEC1 gene methylation status and survival in lung cancer patients. Of the 65 DLECl methylated cases, 37 patients succumbed to the disease, while of the 51 unmethylated

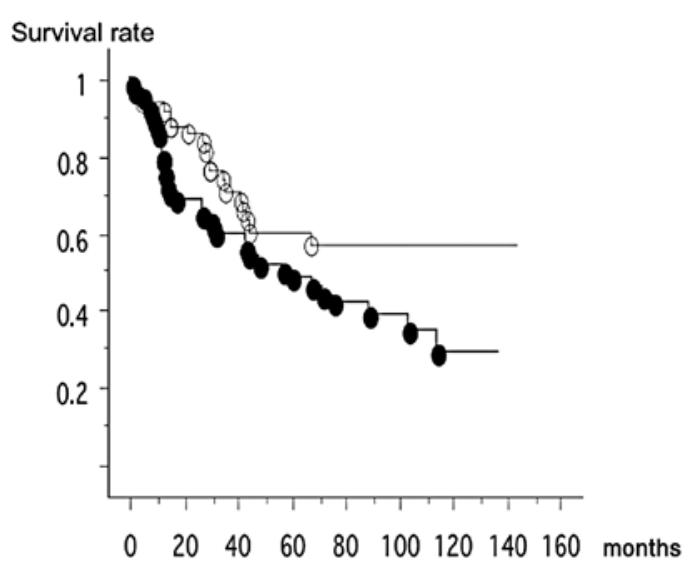

Figure 1. Of the 65 DLEC1 methylated cases, 37 patients succumbed to the disease (mean survival, 62.4 months). Of the 51 unmethylated cases, 18 patients succumbed to the disease (mean survival, 51.1 months). Thus, patients with DLEC1 methylated cancer were significantly associated with poor survival (log-rank test, $\mathrm{p}=0.0407$ ). Black ovals, unmethylated cases; white ovals, methylated cases.

cases, 18 patientts succumbed to the disease. Thus, patients with DLEC1 methylated cancer were significantly associated with poor survival (log-rank test, $\mathrm{p}=0.0407$ ) (Fig. 1). In the 
Table III. Clinicopathological data of 118 lung cancer patients.

\begin{tabular}{|c|c|c|c|}
\hline \multirow[b]{2}{*}{ Factors } & \multicolumn{3}{|c|}{$\mathrm{CDHl}$ gene status } \\
\hline & Methylated cases & Unmethylated cases & p-value \\
\hline Mean age (years) & $66.6 \pm 8.9$ & $62.7 \pm 11.2$ & 0.0491 \\
\hline Stage & & & 0.5669 \\
\hline I & $22(33.8 \%)$ & $21(39.6 \%)$ & \\
\hline II-IV & $43(66.2 \%)$ & $32(60.4 \%)$ & \\
\hline Lymph node metastasis & & & 0.5780 \\
\hline NO & $34(52.3 \%)$ & $31(58.5 \%)$ & \\
\hline $\mathrm{N}^{+}$ & $31(47.7 \%)$ & $22(41.5 \%)$ & \\
\hline Smoking & & & 0.4073 \\
\hline Never smoker & $15(23.1 \%)$ & $16(30.2 \%)$ & \\
\hline Smoker & $50(76.9 \%)$ & $37(69.8 \%)$ & \\
\hline EGFR status & & & 0.2594 \\
\hline Wild-type & $54(83.1 \%)$ & $39(73.6 \%)$ & \\
\hline Mutation & $11(16.9 \%)$ & $14(26.4 \%)$ & \\
\hline Pathological subtypes & & & 0.0514 \\
\hline $\mathrm{SCC}$ & $37(56.9 \%)$ & $40(75.5 \%)$ & \\
\hline Non-SCC & $28(43.1 \%)$ & $13(24.5 \%)$ & \\
\hline Age & & & 0.0275 \\
\hline$\leq 65$ & $24(36.9 \%)$ & $29(54.7 \%)$ & \\
\hline$>65$ & $41(63.1 \%)$ & $24(43.3 \%)$ & \\
\hline Gender & & & 0.5096 \\
\hline Male & $52(80.0 \%)$ & $39(73.6 \%)$ & \\
\hline Female & $13(20.0 \%)$ & $14(26.4 \%)$ & \\
\hline
\end{tabular}

$\mathrm{N}^{+}$, lymph node metastasis positive; SCC, squamous cell carcinoma.

multivariate analysis, pathological stage [stage I vs. stage III-IV, p=0.0038, relative risk, 2.495 (1.342-4.636)] and DLEC1 methylation status were independent prognostic factors $[\mathrm{p}=0.0348$, relative risk, 1.865 (1.046-3.362)].

\section{Discussion}

We demonstrated that the DLEC1 gene was hypermethylated in Japanese lung cancer patients. We did not find any correlations between methylation status and gender, pathological stage and smoking status in Japanese NSCLC patients. However, the DLEC1 methylation status was correlated with survival in Japanese lung cancer patients.

$D L E C 1$ is a candidate tumor-suppressor gene found in multiple cancer types $(3-5,7,15,16)$. DLEC1 suppresses tumor growth or reduces the invasiveness of cancer cells. In ovarian cancer cell lines, the number of colonies formed in DLECI transfectants was significantly lower than that in mock transfectants (8), which showed that DLECl suppressed the growth of ovarian cancer cells and/or inactivation of CDC2 kinase, thereby blocking cells at the $\mathrm{G} 2 / \mathrm{M}$ phase and preventing tumor development in nude mice $(4,5)$. The demethylating agent 5-aza caused the loss of mRNA expression in lung cancer cell lines (16). DLEC1 methylation is cancer-specific, as it was only rarely detected in matched normal lung tissue (5). As there is no antibody available for DLEC1, we were unable to determine whether methylated tumors show a loss or reduced DLEC1 protein expression. However, a loss of DLEC1 RNA expression was previously shown in 8 out of 30 primary lung cancer types, although this loss was not due to gene mutations (6). No correlation between DELC1 methylation and clinical parameters of gastric cancer was found (17), similar to our investigation.

It was demonstrated that pl6 methylation occurs more frequently in squamous cell carcinoma $(16,18)$. These previous results are consistent with our present findings. Several studies have demonstrated a significant association between DNA methylation and tobacco smoking $(20,21)$. Methylation of the p16INK4A gene was induced in rats treated with tobacco-specific NKK[4-N-methyl-N-nitrosamino-1-3-prydil 1-1-butanone (NNK), polyaromatic hydrocarbon] (20). Lung tumors that were induced in F344/N rats after exposure to cigarette smoke by inhalation displayed de novo methylation of p16INK4a (21).

The correlation between $C D H 1$ gene methylation and survival is controversial. Although Nakata et al demonstrated a marginal correlation between $\mathrm{CDH} 1$ methylation and survival ( $\mathrm{p}=0.0473)(16)$ Kim et al demonstrated that $C D H 1$ 
methylation itself did not correlate with either survival or clinicopathological factors (22).

Preclinically, the majority of ovarian cancer cell lines siginificantly up-regulated DLEC1 transcripts after histone deacetylase (HDAC) inhibitor treatment (8). Moreover, exposure to the HDAC inhibitor PXD101 (belinostat) had varying effects on hepatocellular carcinoma cell lines (23). Thus, several HDAC inhibitors were found to exhibit antiproliferative activity and induce apoptosis in human cancer cells (24). Moreover, the restoration of tumor-suppressor genes, such as DLEC1, by HDAC inhibitors may contribute to antitumor effects.

\section{Acknowledgements}

The authors would like to thank Mrs. Tomomi Shibata for the excellent technical assistance. This work was supported by the Grand-in-Aid for Research, Nagoya City University (2006) and Grants-in-Aid for Scientific Research, Japan Society for the Promotion of Science (JSPS) (nos. 21591820 and 21390394).

\section{References}

1. Hung J, Kishimoto Y, Sugio K, et al: Allele-specific chromosome $3 p$ deletions occur at an early stage in the pathogenesis of lung carcinoma. JAMA 273: 558-563, 1995.

2. Wistuba II, Behrens C, Virmani AK, et al: High resolution chromosome $3 p$ allelotyping of human lung cancer and preneoplastic/ preinvasive bronchial epithelium reveals multiple, discontinuous sites of $3 p$ allele loss and three regions of frequent breakpoints. Cancer Res 60: 1949-1960, 2000.

3. Zaborovsky ER, Lerman MI and Minna JD: Tumor suppressor genes on chromosome $3 p$ involved in the pathogenesis of lung and other cancers. Oncogene 21: 6915-6935, 2002.

4. Qiu GH, Salto-Tellez M, Ross JA, et al: The tumor suppressor gene DLEC1 is frequently silenced by DNA methylation in hepatocellular carcinoma and induces G1 arrest in cell cycle. J Hepatol 48: 433-441, 2008.

5. Seng TJ, Currey N, Cooper WA, et al: DLEC1 and MLH1 promoter methylation are associated with poor prognosis in non-small cell lung carcinoma. Br J Cancer 99: 375-382, 2008.

6. Daigo Y, Nishiwaki T, Kawasoe T, Tamari M, Tsuchiya E and Nakamura Y: Molecular cloning of a candidate tumor suppressor gene, DLC1, from chromosome 3p.21.3. Cancer Res 59: 1966-1972, 1999.

7. Kwong J, Chow LS, Wong WK, et al: Epigenetic inactivation of deleted in lung and esophageal cancer 1 gene in nasopharyngeal carcinoma. Genes Chromosomes Cancer 46: 171-180, 2007.

8. Kwong J, Lee JY, Wong KK, et al: Candidate tumor-suppressor gene DLEC1 is frequently downregulated by promoter hypermethylation and histone hypoacetylation in human epithelial ovarian cancer. Neoplasia 8: 268-278, 2006.
9. Kang GH, Lee S, Cho NY, et al: DNA methylation profiles of gastric carcinoma characterized by quantitative DNA methylation analysis. Lab Invest 88: 161-170, 2008.

10. Japan Lung Cancer Society: General Rule for Clinical and Pathological Record of Lung Cancer. 5th edition. Jpn Lung Cancer Soc 5: 1-177, 1999.

11. Paez JG, Janne PA, Lee JC, et al: EGFR mutations in lung cancer: correlation with clinical response to gefitinib therapy. Science 304: 1497-1500, 2004.

12. Endo K, Konishi A, Sasaki H, et al: Epidermal growth factor receptor gene mutation in non-small cell lung cancer using highly sensitive and fast TaqMan PCR assay. Lung Cancer 50: 375-384, 2005.

13. Sasaki H, Shimizu S, Endo K, et al: EGFR and erbB2 mutation status in Japanese lung cancer patients. Int J Cancer 118: 180-184, 2006.

14. Sasaki H, Endo K, Konishi A, et al: EGFR mutation status in Japanese lung cancer patients: genotyping analysis using LighyCycler. Clin Cancer Res 11: 2924-2929, 2005.

15. Smith IM, Mithani SK, Liu C, et al: Novel integrative methods for gene discovery associated with head and neck squamous cell carcinoma development. Arch Otolaryngol Head Neck Surg 135: 487-495, 2009.

16. Nakata S, Sugio K, Uramoto $\mathrm{H}$, et al: The methylation status and protein expression of $\mathrm{CDH} 1, \mathrm{p} 16 \mathrm{INK} 4 \mathrm{~A}$, and fragile histidine triad in nonsmall cell lung carcinoma: epigenetic silencing, clinical features, and prognostic significance. Cancer 106: 2190-2199, 2006.

17. Ying J, Poon FF, Yu J, et al: DLEC1 is a functional 3p22.3 tumor suppressor silenced by promoter $\mathrm{CpG}$ methylation in colon and gastric cancers. Br J Cancer 100: 663-669, 2009.

18. Jarmalaite S, Kannio A, Anttila S, et al: Aberrant p16 promoter methylation in smokers and former smokers with non-small cell lung cancer. Int J Cancer 106: 913-918, 2003.

19. Kim DH, Nelson HH, Wiencke JK, et al: p16(INK4a) and histology-specific methylation of $\mathrm{CpG}$ islands by exposure to tobacco smoke in non-small cell lung cancer. Cancer Res 61: 3419-3424, 2001.

20. Rom WN, Jay JG, Lee TC, Jiang Y and Tchou-Wong KM: Molecular and genetic aspects of lung cancer. Am J Respir Crit Care Med 161: 1355-1367, 2000.

21. Swafford DS, Middleton SK, Palmisano WA, et al: Frequent aberrant methylation of p16INK4a in primary rat lung tumors. Mol Cell Biol 17: 1366-1374, 1997.

22. Kim DS, Kim MJ, Lee JY, et al: Aberrant methylation of E-cadherin and $\mathrm{H}$-cadherin genes in non-small cell lung cancer and its relation to clinicopathologic features. Cancer 110: 2785-2792, 2007.

23. Ma BB, Sung F, Tao Q, et al: The preclinical activity of the histone deacetylase inhibitor PXD101 (belinostat) in hepatocellular carcinoma cell lines. Invest New Drugs. Jan, 27, 2009 (Epub ahead of print).

24. Takai N, Kawamata N, Gui D, Said JW, Miyakawa I and Koeffler HP: Human ovarian carcinoma cells: histone deacetylase inhibitors exhibit antiproliferative activity and potently induce apoptosis. Cancer 15: 2760-2770, 2004. 